\title{
V023 DEALING WITH THE GEOSCIENTIFIC SCALING PROBLEM - AN OBJECT-ORIENTED APPROACH
}

PAUL F.M. DE GROOT and ALBERTUS H. BRIL

De Groot - Bril Earth Sciences BV, Boulevard $1945 \mathrm{nr} 24,7511$ AE Enschede, The Netherlands

\section{Introduction}

Up- and downscaling of geoscientific information represents one of the major challenges in characterising reservoirs. The scaling problem originates from the fact that various types of data and knowledge becomes available during the life cycle of a field. Information with widely varying scales and accuracies is gathered from 0 to 4 dimensions (e.g. core-plug, well $\log _{2} 2 \mathrm{D}$ seismic line, 3D seismic volume, time-lapse seismic). All available information needs to be integrated in order to arrive at consistent results on which economic decisions can be made with confidence.

To relate information from one scale level to another it is imperative that a hierarchical ordering in the geological setting is identified. The ordering facilitates correlations and enables qualitative and quantitative descriptions of rock units at the desired degree of detail. However, in sedimentary geology the hierarchical organisation of rock units is not unique. An overview of some forms of hierarchical systems is given in Table 1.

Table 1.

Hierarchy of rock units in sedimentary geology. After Reijers et.al., 1993.

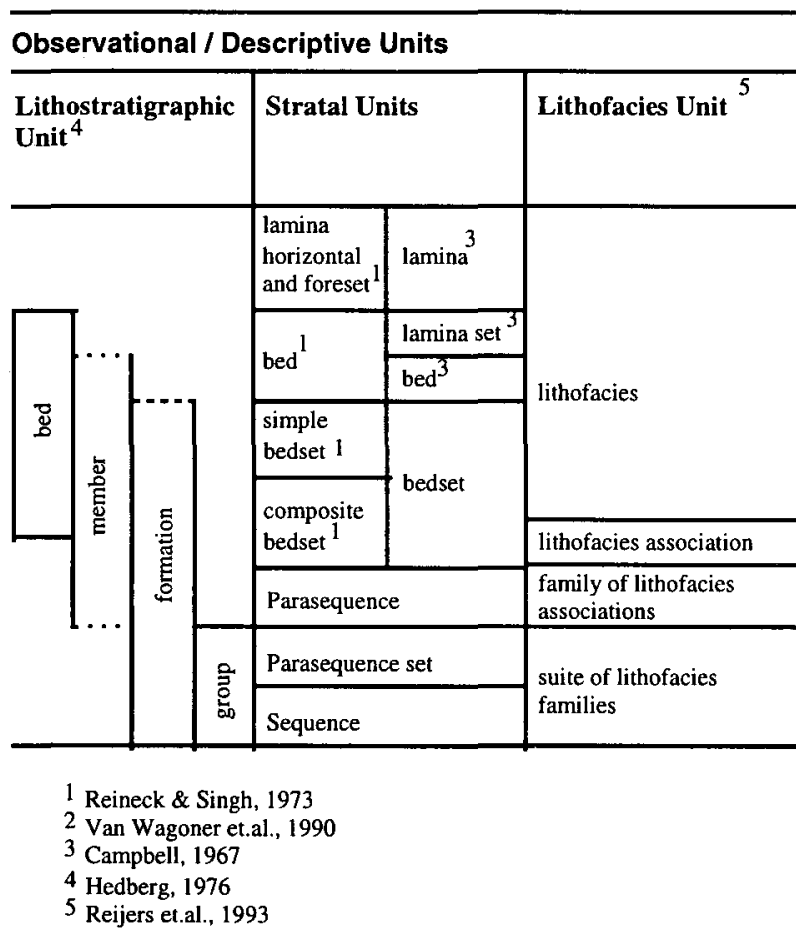

\begin{tabular}{l|l}
\hline \multicolumn{1}{l}{ Interpretation } \\
\hline $\begin{array}{l}\text { Sedimentary } \\
\text { depositional } \\
\text { feature }\end{array}$ & Examples \\
\hline depositional event & avalanche \\
\hline $\begin{array}{l}\text { depositional } \\
\text { process }\end{array}$ & nigrating \\
& sand wave \\
\hline sub-environment & channel \\
\hline major-environinent & alluvial plain \\
\hline supra-environment & continental \\
\hline
\end{tabular}

In this paper an object model for integrating data and knowledge at different scale levels is described. The model has been implemented in a software portfolio in which any hierarchical ordering system as well as all properties and quantities of interest can be captured. Data described in the system can be manipulated at the natural scale levels identified by the geoscientist. Non-linear relationships between quantities of interest and geological objects can be established within the software portfolio a.o. with the help of artificial neural networks. The relationships are then 
used to upscale the information to other natural levels in the hierarchy. Application examples will be presented in this paper.

\section{Integration framework concept}

The object model is implemented in a so-called integration framework. This is a generic description of the zone of interest in terms of framework units, Fig. 1. These are geological objects with attached physical properties (nonnumeric) and quantities (numeric). The objects are defined at natural scale levels corresponding to a tree with nodes and leaves. Depending on the type of application objects can be defined from the basin-scale down to the pores and grains level. Each object is related to its parent and its children, hence to the hierarchical system.
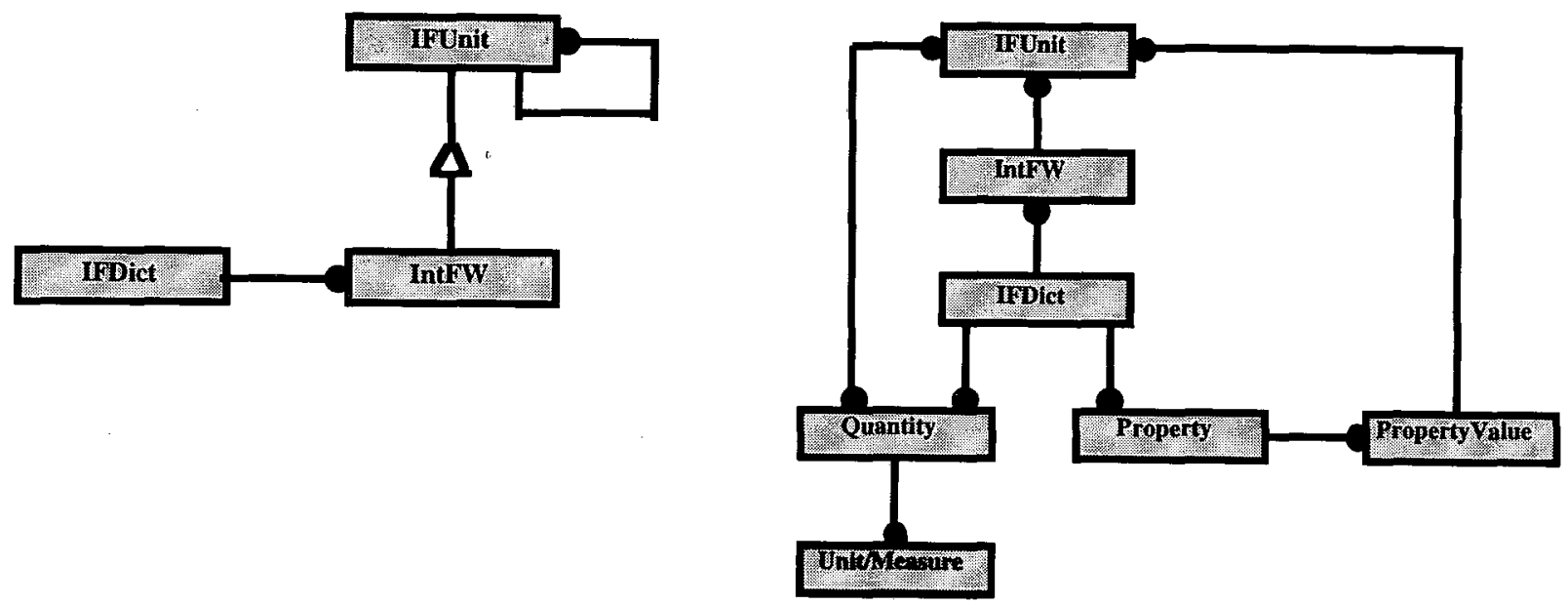

Fig 1. Core objects and data items in the integration framework object model (OMT notation)

In the integration framework each object is given a user-defined reference name as well as a user-defined unit code (a mnemonic). In realisations of the integration framework geological objects are uniquely identified through unitIDs (unit identifiers). These consist of a concatenation of unit codes with unique occurrence numbers.

\section{Applications}

Examples will be shown of upscaling information via the integration framework concept. So far, the integration framework has been used in seismic interpretation studies for relating low(er) resolution seismic signals to highresolution stratigraphic and well log information. Examples are conventional lateral prediction studies, seismic pattern analysis, feasibility studies, sensitivity analysis and testing seismic inversion algorithms (e.g. de Groot \& Bril, 1996). It is also feasible to use the concept in rock physics and petro-physics applications, however. For example to establish empirical relationships between rock-sample porosities and well-log porosities, or between porosities and permeabilities.

\section{References}

Campbell, C.V., 1967. Lamina and laminaset, bed and bedset. Sedimentology 8, 7-26.

de Groot, P.F.M., 1995. Seismic reservoir characterisation employing factual and simulated wells: PhD thesis. Delft University Press.

de Groot, P.F.M. and Bril, A.H., 1996. The use of pseudo-wells in seismic interpretation studies. EAGE annual meeting and conference, June 1996, Amsterdam.

Hedberg, H.D., 1976. International Stratigraphic. Wiley, New York, 200 p.

Reineck, H.E. and Singh, I.B., 1973. Depositional Sedimentary Environments - With Reference to Terrigeneous Clastics. Springer-Verlag, Berlin, $551 \mathrm{p}$.

Reijers, T.A. et. al., 1993. Lithofacies and their interpretation: a guide to standardised description of sedimentary deposits. Mededelingen van de Rijks Geologische Dienst, Report Nr49 1993.

Sherrif, R.E.(ed.), 1992. Reservoir geophysics: Investigations in Geophysics, 7. Soc. Expl. Geophys.

Wagoner, Van, et.al., 1990. Siliciclastic Sequence Stratigraphy in Well Logs Cores and Outcrops. AAPG Methods in Exploration Series No. 7. Society of Sedimentary Geology Special Publications 42 (1988). Sea Level Changes - An Integrated Approach. American Association of Petroleum Geologists. 